\title{
Early results of extra-aortic annuloplasty ring implantation on aortic annular dimensions
}

\author{
Lauren Basmadjian, MD, ${ }^{\mathrm{a}}$ Arsène J. Basmadjian, MD, MSc, ${ }^{\mathrm{b}}$ Louis-Mathieu Stevens, MD, PhD, ${ }^{c}$ \\ François-Pierre Mongeon, MD, ${ }^{\mathrm{b}}$ Raymond Cartier, MD, ${ }^{\mathrm{a}}$ Nancy Poirier, MD, ${ }^{\mathrm{a}}$ and \\ Ismail El Hamamsy, $\mathrm{MD}, \mathrm{PhD}^{\mathrm{a}}$
}

\begin{abstract}
Objectives: Dilatation of the aortic annulus is a cause of recurrent aortic regurgitation following the Ross or Yacoub procedures. Use of an extra-aortic annuloplasty ring is a potentially useful adjunct procedure. The aim of this study was to analyze the early effectiveness and mid-term stability of this surgical approach.

Methods: From 2011 to 2015, 50 patients (mean age, $43 \pm 14$ years) underwent adjunct extra-aortic annuloplasty ring implantation $(\mathrm{n}=39$ Dacron rings and $\mathrm{n}=11$ ExAo rings [CORONEO Inc, Montreal, Canada]). Median ring size was $28 \mathrm{~mm}$ (range, 27-32 mm). All patients had aortic regurgitation or a dilated aortic annulus. Concomitant surgical procedure was a valve-sparing remodeling procedure $(\mathrm{n}=32)$ or a Ross procedure $(\mathrm{n}=18)$. Baseline and follow-up echocardiographic systolic and diastolic aortic annular dimensions were prospectively collected. Longitudinal analyses were performed using mixed-effect models. Median follow-up was 12 months (98\% complete).

Results: Use of an extra-aortic annuloplasty ring resulted in a significant decrease in both systolic ( $27.9 \pm 0.5 \mathrm{~mm}$ preoperatively vs $23.6 \pm 0.3 \mathrm{~mm}$ at discharge, $P<.001)$ and diastolic $(24.8 \pm 0.4 \mathrm{~mm}$ preoperatively vs $20.3 \pm 0.3 \mathrm{~mm}$ at discharge, $P<.001)$ dimensions. Mean systolic and diastolic dimensions remained statistically unchanged up to 2 years postoperatively, compared with their predischarge values. Systolic expansion of the annulus was conserved early after surgery (16\% systolic expansion) and preserved up to 2 years after ring implantation.
\end{abstract}

Conclusions: Use of an extra-aortic annuloplasty ring is effective at reducing annular diameters. This remains stable at mid-term follow-up, with preservation of aortic annular dynamics. Longer-term studies are required to determine the continued stability and impact on long-term clinical outcomes. (J Thorac Cardiovasc Surg 2016;151:1280-5)

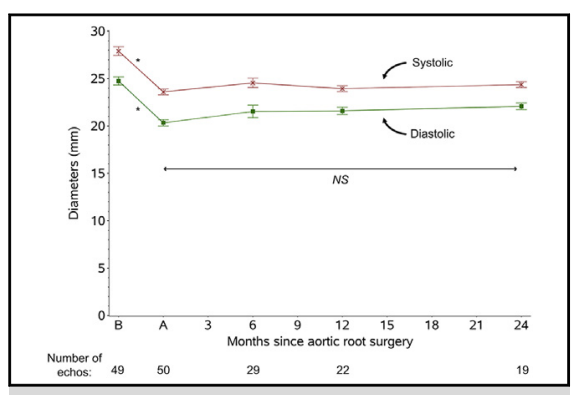

Changes in systolic and diastolic annular dimensions after extra-aortic ring annuloplasty.

\section{Central Message}

Extra-aortic ring annuloplasty is a novel technique that represents an effective and stable adjunct to aortic root surgery.

\section{Perspective}

Late dilatation of the aortic annulus is one of the main limitations of the Yacoub or Ross procedures, especially in patients with preoperative annular dilatation or aortic regurgitation. This study demonstrates the efficacy of adjunct extra-aortic ring annuloplasty in reducing and stabilizing the aortoventricular junction. This should have a major impact in mitigating the risk of late reoperation.

See Editorial Commentary page 1286.
Various surgical techniques have been proposed to tailor the aortic annular base in aortic root reconstructive surgery, including intertrigonal sutures, subcommissural reduction, partial bands, and a single circumferential suture. The

From the ${ }^{\mathrm{a} D i v i s i o n}$ of Cardiac Surgery and ${ }^{\mathrm{b}}$ Department of Medicine, Montreal Heart Institute, and ${ }^{c}$ Division of Cardiac Surgery, CHUM, University of Montreal, Quebec, Canada.

Received for publication July 20, 2015; revisions received Nov 23, 2015; accepted for publication Dec 2, 2015; available ahead of print Jan 13, 2016.

Address for reprints: Ismail El Hamamsy, MD, PhD, Associate Professor, Division of Cardiac Surgery, Surgical Director, Aortic and Connective Tissue Clinic, Montreal Heart Institute, Université de Montréal, 5000 Bélanger St, Montreal, Quebec H1T 1C8, Canada (E-mail: i.elhamamsy@icm-mhi.org).

$0022-5223 / \$ 36.00$

Copyright (c) 2016 by The American Association for Thoracic Surgery

http://dx.doi.org/10.1016/j.jtcvs.2015.12.014 main objective of these approaches is to reduce the size of the aortoventricular junction (the basal ring) or to prevent its long-term dilatation. This represents the main difference between the 2 main aortic valve-sparing techniques. Although the remodeling technique provides more physiologic valve opening and closing dynamics because of the creation of neo-sinuses of Valsalva, ${ }^{1-4}$ the aortoventricular junction is at risk of late dilatation, a

Scanning this QR code will take you to supplemental data for this article. 
potential cause of recurrent aortic regurgitation and reoperation. In contrast, the reimplantation technique integrates the aortoventricular junction in the proximal suture line, thus preventing late dilatation of the annular base. In recent years, Lansac and colleagues ${ }^{5,6}$ have proposed a surgical technique combining the benefits of both approaches: remodeling of the aortic root with an adjunct extra-aortic annuloplasty using an expansible aortic ring (ExAo; CORONEO Inc, Montreal, Canada). In a multicenter study evaluating predischarge echocardiographic examinations, this has proven effective in reducing the aortoventricular junction diameter while preserving aortic annulus expansion during systole (10\%-15\% expansibility). ${ }^{\top}$

We have adopted this technique for different types of aortic valve/root operations in patients with a dilated aortic annulus $(>25 \mathrm{~mm})$. Because the ExAo ring is not yet approved for use in Canada, we have mainly used Dacron rings obtained from Dacron tube grafts (Vascutek, Terumo, Japan) for extra-aortic annuloplasties. To date, no studies have examined the effectiveness and the mid-term stability of this surgical technique in achieving and maintaining aortic annular diameter reduction. The main concern is dilatation of the Dacron ring. Indeed, it has been shown that Dacron expands after implantation by up to $20 \%$ of its original diameter when used as an ascending aortic conduit, reaching its peak diameter increase within the first 18 months after implantation. ${ }^{8}$ Although expansion of an aortic conduit by $20 \%$ may not be of clinical significance at the level of the ascending aorta, a similar expansion at the level of the aortic annulus would constitute a significant drawback. Therefore, the aim of this study was to assess the efficacy of a ring annuloplasty using a Dacron ring or an ExAo ring in reducing aortic annular dimensions and the mid-term stability of this surgical technique. In addition, aortic annular dynamics as defined by systolic annular expansion were evaluated.

\section{MATERIALS AND METHODS Study Population}

From 2011 to 2015, 50 extra-aortic annuloplasty ring implantations were performed in 50 consecutive patients by a single surgeon (IEH). The mean age of the patients was $43 \pm 14$ years $(90 \%$ were male) (Table 1). All patients had aortic regurgitation or a dilated aortic annulus. A valve-sparing procedure was considered in all cases. In cases of extensive cusp calcification, severe cusp retraction with insufficient geometric height or torn fenestrations, a Ross procedure was performed. The surgical procedure was a valve-sparing root remodeling operation $(\mathrm{n}=32)$ or a Ross procedure $(\mathrm{n}=18)$ (Appendix E1 shows patient characteristics). The technique used for the Ross procedure was a total root replacement in all cases. The autograft root was placed in an intra-annular position using single interrupted sutures. Details of the surgical technique have been described. ${ }^{9}$ Median clinical and echocardiographic follow-up was 12 months and $98 \%$ complete. The study was approved by the Montreal Heart Institute Institutional Review Board, and a waiver of consent was obtained.
TABLE 1. Patient characteristics $(\mathbf{N}=\mathbf{5 0}$ patients $)$

\begin{tabular}{|c|c|}
\hline \multicolumn{2}{|l|}{ Patient characteristics } \\
\hline Mean age (y) & $43 \pm 14$ \\
\hline Male gender, $\mathrm{n}(\%)$ & $45(90 \%)$ \\
\hline \multicolumn{2}{|l|}{ Comorbidities } \\
\hline Hypertension, n (\%) & $16(32 \%)$ \\
\hline Diabetes, $\mathrm{n}(\%)$ & $2(4 \%)$ \\
\hline Dyslipidemia, n (\%) & $7(14 \%)$ \\
\hline Obesity, n $(\%)$ & $12(24 \%)$ \\
\hline Pulmonary hypertension, $\mathrm{n}(\%)$ & $1(2 \%)$ \\
\hline \multicolumn{2}{|l|}{ Aortic valve phenotype } \\
\hline Tricuspid, n (\%) & $20(40 \%)$ \\
\hline Bicuspid, n (\%) & $21(42 \%)$ \\
\hline Unicuspid, n (\%) & $8(16 \%)$ \\
\hline Quadricuspid, n (\%) & $1(2 \%)$ \\
\hline \multicolumn{2}{|l|}{ Connective tissue disorder } \\
\hline Marfan syndrome, n (\%) & $7(14 \%)$ \\
\hline Loeys-Dietz syndrome, $\mathrm{n}(\%)$ & $1(2 \%)$ \\
\hline \multicolumn{2}{|l|}{ Principal valve lesion } \\
\hline Aortic regurgitation, n (\%) & $31(62 \%)$ \\
\hline Mixed aortic stenosis/regurgitation, n (\%) & $19(38 \%)$ \\
\hline \multicolumn{2}{|l|}{ Operative procedure } \\
\hline Valve-sparing root remodeling, $\mathrm{n}(\%)$ & $32(64 \%)$ \\
\hline Ross procedure, n (\%) & $18(36 \%)$ \\
\hline \multicolumn{2}{|l|}{ Ring type } \\
\hline Dacron ring, $\mathrm{n}(\%)$ & $39(78 \%)$ \\
\hline ExAo ring (CORONEO Inc, Montreal, Canada), n (\%) & $11(22 \%)$ \\
\hline \multicolumn{2}{|l|}{ Concomitant procedures } \\
\hline Hemiarch replacement, n (\%) & $8(16 \%)$ \\
\hline Mitral valve repair, n (\%) & $5(10 \%)$ \\
\hline Coronary bypass surgery, $\mathrm{n}(\%)$ & $3(6 \%)$ \\
\hline
\end{tabular}

\section{Ring Implantation and Diameter Selection Technique}

The surgical approach was identical in all patients. ${ }^{10}$ After dissecting around the aortic root to the level of the aortoventricular junction (basal ring), six 2-0 U pledgeted Ethibond sutures (Ethicon Inc, Somerville, NJ) are passed from inside out, along a horizontal plane. This plane corresponds to the basal ring of the aortic root, approximately $2 \mathrm{~mm}$ below the nadir of the aortic valve cusps. Care is taken to avoid the conduction tissue at the level of the membranous septum by raising that suture 1 to $2 \mathrm{~mm}$ higher than the level of the others (Figure 1). Once the sutures are all passed, a Dacron ring approximately 5 to $6 \mathrm{~mm}$ larger than the desired aortic annular diameter is selected, to account for the thickness of tissue between the ring and the inner diameter. The target annular diameter is determined according to the patient's sex and body surface area, aiming for a normal aortic annular diameter $(20-25 \mathrm{~mm})^{11}$ measured using a Hegar

TABLE 2. Echocardiographic changes in systolic expansion and degree of aortic regurgitation up to 2 years after extra-aortic ring implantation

\begin{tabular}{|c|c|c|c|c|c|}
\hline & $\begin{array}{c}\text { Preoperative } \\
(n=49)\end{array}$ & $\begin{array}{c}\text { Discharge } \\
(\mathbf{n}=\mathbf{5 0})\end{array}$ & $\begin{array}{c}6 \text { mo } \\
(n=29)\end{array}$ & $\begin{array}{c}1 \mathbf{y} \\
(n=22)\end{array}$ & $\begin{array}{c}2 y \\
(n=19)\end{array}$ \\
\hline $\begin{array}{l}\text { Systolic } \\
\quad \text { expansion }(\%)\end{array}$ & $12.5 \%$ & $16 \%$ & $12 \%$ & $11 \%$ & $10 \%$ \\
\hline $\begin{array}{l}\text { Aortic } \\
\text { regurgitation }\end{array}$ & $2+$ & Trace* & Trace* & Trace* & Trace* \\
\hline
\end{tabular}




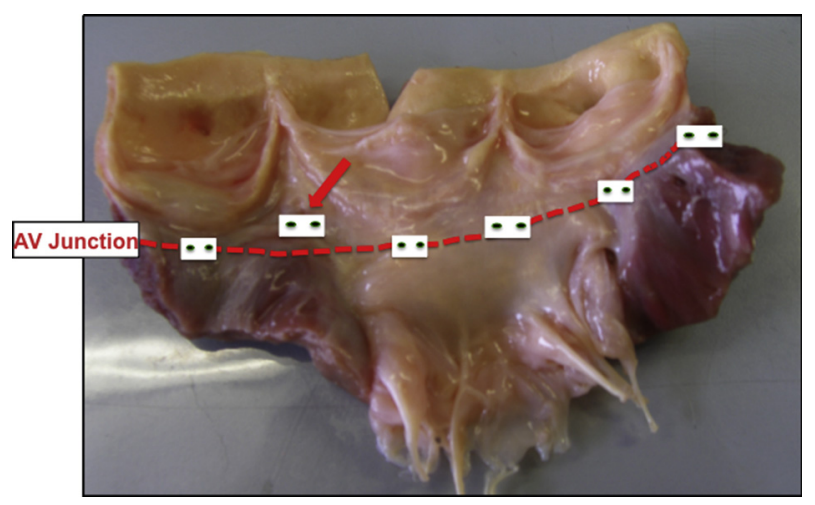

FIGURE 1. Schematic representation of distribution of the 6 annuloplasty sutures used to perform the extra-aortic annuloplasty. Care is taken to place the suture 1 to $2 \mathrm{~mm}$ higher than the plane of the basal ring at the level of the membranous septum to avoid the conduction system (arrow). $A V$, Aortoventricular.

dilator. In patients with a body surface area less than $1.8 \mathrm{~m}^{2}$, we aimed for an annulus of 20 to $21 \mathrm{~mm}$; in patients with a body surface area between 1.8 and $2.2 \mathrm{~m}^{2}$, we aimed for an annulus of 22 to $23 \mathrm{~mm}$; and in patients with a body surface area greater than $2.2 \mathrm{~m}^{2}$, we aimed for an annulus of 24 to $25 \mathrm{~mm}$. The ring is then tied around a Hegar dilator placed inside the aortoventricular junction to avoid excessive reduction of the annular dimensions. Therefore, to obtain a $23-\mathrm{mm}$ annular diameter, a $28-\mathrm{mm}$ ring is used and tied around a 23-mm Hegar dilator.

\section{Ring Types}

Two different types of extra-aortic rings were used in this patient cohort. The most frequently used was a standard Dacron ring $(\mathrm{n}=39)$. By using a Dacron graft, a circular ring approximately $4 \mathrm{~mm}$ in height was used, corresponding to 3 to 4 folds on the graft. In addition, commercially available ExAo rings were used in 11 patients. The latter are not yet approved for use in Canada and therefore were used only in certain patients under the Special Access Program from Health Canada, following informed patient consent. Use of either ring type was based on surgeon preference. Patient characteristics according to ring type are presented in Appendix E2.

\section{Echocardiographic Measurements}

Comprehensive transthoracic echocardiographic examinations were performed at baseline (preoperatively), before discharge, 6 to 12 months after surgery, and annually thereafter. All echocardiograms were individually analyzed twice by 2 of the authors (LB and AJB). When the measurements differed by more than $10 \%$, they were independently repeated. Interobserver and intraobserver variability were assessed and were both less than $10 \%$. Aortic dimensions were assessed in the parasternal long-axis view 2-dimensional still-frame. Systolic annular diameter was measured at the T-wave on electrocardiogram, corresponding to the open aortic valve, and diastolic annular diameter was measured near the QRS with a closed aortic valve. Measurements were performed using the inner edge to inner edge technique at the base of leaflet attachment to the ventricular wall. Aortic regurgitation severity was graded using standard echocardiographic criteria as defined by the European Association of Echocardiography and the American Society of Echocardiography. ${ }^{12,13}$ Systolic expansion of the annulus was calculated as the percentage of annular diameter increase from diastole to systole.

\section{Statistical Analysis}

Data are expressed as mean \pm standard deviation or median (interquartile range) for continuous variables and frequency (\%) for categoric variables. Random effects models were used to assess changes in echocardiographic measures over time and account for the correlation between repeated follow-up measurements (MIXED procedures in SAS software, version 9.3; SAS Institute, Inc, Cary, NC). Piecewise linear random effect models using time as a continuous measure and random effect for the patient were constructed with time knots at baseline preoperatively ("B"), postoperatively before discharge ("A"), and at 6 , 12 , and 24 months postoperatively. For patients with missing echocardiographic measurements at a given time point, the outcome data were considered to be missing at random. Because of the small number of patients in the CORONEO arm, comparisons of ring group demographics and outcomes are not presented in the "Results" section, but only provided as exploratory analyses in the "Discussion" section.

\section{RESULTS \\ Perioperative Results}

There were no mortalities in the entire cohort and no complications related to the annuloplasty technique. Median implanted ring size was $28 \mathrm{~mm}$ (range, 27-32 mm). Mean preoperative systolic and diastolic aortic annular diameters were $27.9 \pm 0.5 \mathrm{~mm}$ and $24.8 \pm 0.4 \mathrm{~mm}$, respectively. Overall, the use of an extra-aortic annuloplasty ring resulted in a significant decrease in both systolic $(27.9 \pm 0.5 \mathrm{~mm}$ preoperatively vs $23.6 \pm 0.3 \mathrm{~mm}$ at discharge, $P<.001)$ and diastolic $(24.8 \pm 0.4 \mathrm{~mm}$ preoperatively vs $20.3 \pm 0.3 \mathrm{~mm}$ at discharge, $P<.001$ ) dimensions (Figure 2).

\section{Mid-Term Outcomes}

Mid-term follow-up showed stability of the annular reduction (Figure 2). At 1 and 2 years, mean systolic and diastolic dimensions remained unchanged compared with their early postoperative values in systole $(23.9 \pm 0.3 \mathrm{~mm}$ at 1 year and $24.4 \pm 0.3 \mathrm{~mm}$ at 2 years vs $23.6 \pm 0.3 \mathrm{~mm}$

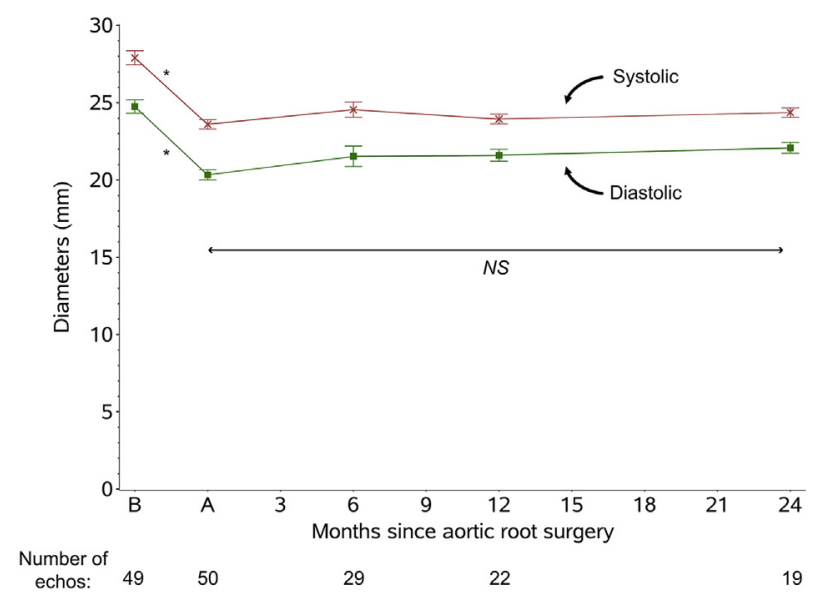

FIGURE 2. Changes in systolic and diastolic aortic annular dimensions after extra-aortic ring annuloplasty. Estimates $\pm 95 \%$ confidence interval from the piecewise linear random effect models are provided at each time knot: baseline preoperatively (B), postoperatively before discharge (A), and at 6,12 , and 24 months postoperatively. $* P<.001$ versus preoperative. There were no significant changes in systolic or diastolic dimensions over time (up to 2 years). NS, Not significant. 
at discharge, $P=$ not significant) and in diastole $(21.5 \pm 0.3 \mathrm{~mm}$ at 1 years and $22.1 \pm 0.3 \mathrm{~mm}$ at 2 years vs $20.3 \pm 0.3 \mathrm{~mm}$ at discharge, $P=$ not significant) (Table 2).

\section{Aortic Root Expansion}

Systolic expansion of the annulus was conserved early after surgery (16\% systolic expansion) and preserved up to 2 years after ring implantation ( $10 \%$ systolic expansion). At 2 years, both types of rings provide systolic expansion within the physiologic range $(5 \%-15 \%)$.

\section{Aortic Valve Function}

The median preoperative grade of aortic regurgitation was $2 / 4$. After surgery, all patients had no to trace aortic regurgitation. At 2 years, no patients had greater than $1+$ aortic regurgitation.

\section{DISCUSSION}

The main findings from this study are that an aortic annuloplasty using an extra-aortic ring is effective at reducing annular dimensions and remains stable at mid-term follow-up. In addition, systolic expansion of the aortic annulus during the cardiac cycle is preserved. These findings confirm the benefits of this surgical approach, which was originally proposed by Lansac and colleagues ${ }^{14}$ to mitigate the main limitation of the original remodeling technique: progressive dilatation of the aortoventricular junction. Indeed, looking at various studies comparing the durability and freedom from reoperation after reimplantation versus remodeling procedures, the former seems to be more durable mainly because of the annular stabilization, which is inherent to reimplantation. ${ }^{15,16}$ This has led many groups to abandon the remodeling procedure, despite a more physiologic reconstruction of the root and less traumatic opening and closing dynamics of the aortic valve cusps. ${ }^{4,17,18}$ In fact, technical iterations of the reimplantation procedure have aimed at recreating neo-sinuses of Valsalva. ${ }^{17,19,20}$ The extra-aortic annuloplasty technique, which in essence corresponds to the proximal suture line in a reimplantation procedure, aims at combining the best of both procedures.

The surgical technique described by Lansac and colleagues $^{6}$ uses a commercially available expansible extra-aortic ring (ExAo). Because this ring is not yet approved for use in Canada except under a special access program from Health Canada, the majority of cases in this study were performed using a Dacron ring, which was cut out from standard Dacron tube grafts. One of the characteristics of Dacron when used as a vascular conduit is its potential for dilatation. This represented a major concern when using it as an annuloplasty ring because mild dilatation could annul its role as an adjunct to reduce and stabilize the diameter of the aortoventricular junction. When used as an aortic conduit, the potential for Dacron to expand over months after implantation was shown by Etz and colleagues. ${ }^{8}$ With the use of serial imaging, they described an increase in diameter of up to $20 \%$, with maximum expansion in the first 12 to 18 months after implantation, followed by a very slow and steady increase of $1 \%$ per year. If similar expansion rates occurred with the extraaortic ring, this would transform a $28-\mathrm{mm}$ ring into a 34-mm ring after 12 to 18 months, which would render the annuloplasty inefficient at stabilizing the aortoventricular junction. The observed absence of expansion may be due to the fact that, unlike the Dacron aortic conduit, the extra-aortic ring is fixed with 6 anchoring sutures, which significantly limit its potential for radial expansion. This is in many ways similar to the observation of minimal expansibility or radial elasticity of a Dacron graft after a root reimplantation procedure. In addition, the height of the ring is significantly shorter than an aortic graft, which would make it less prone to dilatation.

The aortoventricular junction has long been recognized as an important determinant of durability in patients undergoing a remodeling procedure and in those with aortic regurgitation undergoing a Ross procedure. In both these patient populations, an aortoventricular junction greater than $28 \mathrm{~mm}$ is predictive of higher rates of recurrent aortic regurgitation and reoperation. ${ }^{21}$ In addition, the presence of preoperative aortic regurgitation in patients undergoing the Ross procedure is similarly predictive of a higher rate of reoperation. $^{22,23}$ The reason for the higher rates of recurrence of aortic regurgitation may be an incomplete reduction of annular dimensions at the time of surgery or recurrent dilatation of the annulus because of lack of adequate support at the time of surgery. The current study suggests that the extra-aortic annuloplasty technique using a ring provides an effective means of accurately and reproducibly reducing the annular diameter at the time of surgery, with no significant change in annular dimensions at mid-term follow-up. Therefore, we use this approach in all patients undergoing a valve-sparing root remodeling or a Ross procedure for aortic regurgitation (in cases where the valve cannot be preserved). Although annular dimensions remain stable up to 2 years after the operation and there is no evidence of significant aortic regurgitation recurrence, longer-term follow-up is required on a larger cohort of patients to assess continued stability and its impact on clinically relevant outcomes, such as long-term freedom from aortic valve regurgitation and reoperation.

In normal aortic root functional dynamics, the aortoventricular junction expands by $5 \%$ to $15 \%$ during the systolic phase. $^{24,25}$ The ExAo ring was designed to preserve expansibility of the aortic root at the annular level, which has been demonstrated in the CAVIAAR registry looking at all patients undergoing root remodeling. ${ }^{7}$ Our data confirm these findings with preserved systolic expansion 
of the annulus up to 2 years after implantation, within the physiologic range (12\% at discharge and $10 \%$ at 2 years). Of note, Dacron rings showed comparable expansibility at discharge (17\% systolic expansion), which may be a result of the inherent deformational potential of Dacron, allowing for expansion under radial stress, but also may be due to expansion of the aortoventricular junction in the spaces between the 6 subannular stitches. In a recent study, de Kerchove and colleagues ${ }^{26}$ demonstrated preserved annular dynamics with the reimplantation procedure using 9-12 pledgeted stitches, thus leaving little space between the sutures. This suggests that Dacron holds deformational potential, which allows for expansion and recoil, but not permanent dilatation. Nevertheless, in our study, although not statistically significant, there was a decrease in the degree of systolic expansion of the annulus with the Dacron rings at 2 years ( $9 \%$ vs $17 \%$ at discharge). Although this still remains within physiologic range, it mandates continued evaluation to determine whether annular expansibility will remain stable or continue to decrease with longer follow-up.

Although the changes in systolic dimensions were interpreted as systolic expansion of the aortic annulus, this also may be due to a change in spatial conformation of the aortic annulus in systole. Indeed, it is now well established that the aortic annulus is an oval structure, which becomes more circular in systole. The transition from oval to circular leads to an expansion of the shorter diameter in the diastolic oval shape. Because systolic expansion was measured using 2-dimensional echocardiography, this represents a potential alternative or complementary explanation for the change in dimensions. To accurately determine the potential expansibility of the annuloplasty ring, aortic annular area using 3-dimensional echocardiography or computed tomography imaging would better address the question. Indeed, it may be argued that the change in diameter could not represent deformational potential of Dacron, otherwise Dacron would demonstrate a Windkessel effect when used as a tube graft, which is not the case. However, that remains to be determined for the ExAo ring, which is by design an expansible ring.

\section{CONCLUSIONS}

Our results demonstrate the efficacy of using an extra-aortic annuloplasty ring in reducing aortic annular dimensions, with stability observed at mid-term follow-up. In addition, annular systolic expansion was preserved using this surgical approach. Use of the ExAo ring appears to better maintain annular expansion than a Dacron ring. This simple technique should be considered as a useful adjunct in patients in whom intraoperative or future annular dilatation is a concern. Continued follow-up is required to confirm the long-term stability of the extra-aortic annuloplasty and its impact on long-term clinical outcomes in patients undergoing aortic root interventions.

\section{Conflict of Interest Statement}

Authors have nothing to disclose with regard to commercial support.

\section{References}

1. Ranga A, Bouchot O, Mongrain R, Ugolini P, Cartier R. Computational simulations of the aortic valve validated by imaging data: evaluation of valve-sparing techniques. Interact Cardiovasc Thorac Surg. 2006;5:373-8.

2. Graeter TP, Fries R, Aicher D, Reul H, Schmitz C, Schafers HJ. In-vitro comparison of aortic valve hemodynamics between aortic root remodeling and aortic valve reimplantation. J Heart Valve Dis. 2006;15:329-35.

3. Fries R, Graeter T, Aicher D, Reul H, Schmitz C, Böhm M, et al. In vitro comparison of aortic valve movement after valve-preserving aortic replacement. J Thorac Cardiovasc Surg. 2006;132:32-7.

4. Leyh RG, Schmidtke C, Sievers H-H, Yacoub MH. Opening and closing characteristics of the aortic valve after different types of valve-preserving surgery. Circulation. 1999;100:2153-60.

5. Lansac E, Di Centa I, Bonnet N, Leprince P, Rama A, Acar C, et al. Aortic prosthetic ring annuloplasty: a useful adjunct to a standardized aortic valvesparing procedure? Eur J Cardiothorac Surg. 2006;29:537-44.

6. Lansac E, Di Centa I, Raoux F, Bulman-Fleming N, Ranga A, Abed A, et al. An expansible aortic ring for a physiological approach to conservative aortic valve surgery. J Thorac Cardiovasc Surg. 2009;138:718-24.

7. Wuliya M, Sleilaty G, Di Centa I, Khelil N, Berrebi A, Czitrom D, et al. An expansible aortic ring to preserve aortic root dynamics after aortic valve repair. Eur J Cardiothorac Surg. 2015;47:482-90.

8. Etz CD, Homann T, Silovitz D, Bodian CA, Luehr M, Di Luozzo G, et al. Vascular graft replacement of the ascending and descending aorta: do Dacron grafts grow? Ann Thorac Surg. 2007;84:1206-13.

9. Forcillo J, Cikirikcioglu M, Poirier N, El-Hamamsy I. The Ross procedure: total root technique. Multimed Man Cardiothorac Surg. 2014;2014. doi: 10.1093/ mmcts/mmu018:1-6.

10. Lansac E, Di Centa I, Vojacek J, Nijs J, Hlubocky J, Mecozzi G, et al. Valve sparing root replacement: the remodeling technique with external ring annuloplasty. Ann Cardiothoracic Surg. 2013;2:117-23.

11. Capps SB, Elkins RC, Fronk DM. Body surface area as a predictor of aortic and pulmonary valve diameter. J Thorac Cardiovasc Surg. 2000;119:975-82.

12. Baumgartner H, Hung J, Bermejo J, Chambers JB, Evangelista A, Griffin BP, et al. Echocardiographic assessment of valve stenosis: EAE/ASE recommendations for clinical practice. Eur J Echocardiogr. 2009;10:1-25.

13. Zoghbi WA, Enriquez-Sarano M, Foster E, Grayburn PA, Kraft CD, Levine RA, et al. Recommendations for evaluation of the severity of native valvular regurgitation with two-dimensional and Doppler echocardiography. J Am Soc Echocardiogr. 2003;16:777-802.

14. Lansac E, Di Centa I, Varnous S, Rama A, Jault F, Duran CM, et al. External aortic annuloplasty ring for valve-sparing procedures. Ann Thorac Surg. 2005;79:356-8.

15. David TE, Feindel CM, David CM, Manlhiot C. A quarter of a century of experience with aortic valve-sparing operations. J Thorac Cardiovasc Surg. 2014;148:872-80.

16. David TE, Armstrong S, Maganti M, Colman J, Bradley TJ. Long-term results of aortic valve-sparing operations in patients with Marfan syndrome. J Thorac Cardiovasc Surg. 2009;138:859-64.

17. Grande-Allen KJ, Cochran RP, Reinhall PG, Kunzelman KS. Re-creation of sinuses is important for sparing the aortic valve: a finite element study. J Thorac Cardiovasc Surg. 2000;119:753-63.

18. Kunzelman KS, Grande KJ, David TE, Cochran RP, Verrier ED. Aortic root and valve relationships. Impact on surgical repair. J Thorac Cardiovasc Surg. 1994; 107:162-70.

19. Demers P, Miller DC. Simple modification of "T. David-V" valve-sparing aortic root replacement to create graft pseudosinuses. Ann Thorac Surg. 2004;78:1479-81.

20. Schmidtke C, Sievers HH, Frydrychowicz A, Petersen M, Scharfschwerdt M, Karluss A, et al. First clinical results with the new sinus prosthesis used for valve-sparing aortic root replacement. Eur J Cardiothorac Surg. 2013;43:585-90.

21. David TE, Woo A, Armstrong S, Maganti M. When is the Ross operation a good option to treat aortic valve disease? J Thorac Cardiovasc Surg. 2010; 139:68-75. 
22. Charitos EI, Takkenberg JJ, Hanke T, Gorski A, Botha C, Franke U, et al. Reoperations on the pulmonary autograft and pulmonary homograft after the Ross procedure: an update on the German Dutch Ross Registry. J Thorac Cardiovasc Surg. 2012;144:813-23.

23. Mastrobuoni S, de Kerchove L, Solari S, Astarci P, Poncelet A, Noirhomme P, et al. The Ross procedure in young adults: over 20 years of experience at our institution. Eur J Cardiothorac Surg. March 3, 2015 [Epub ahead of print].

24. Lansac E, Lim HS, Shomura Y, Lim KH, Rice NT, Goetz W, et al. A four-dimensional study of the aortic root dynamics. Eur J Cardiothorac Surg. 2002;22:497-503.
25. Cheng A, Dagum P, Miller DC. Aortic root dynamics and surgery: from craft to science. Philos Trans R Soc Lond B Biol Sci. 2007;362:1407-19.

26. de Kerchove L, Vismara R, Mangini A, Fiore GB, Price J, Noirhomme P, et al In vitro comparison of three techniques for ventriculo-aortic junction annuloplasty. Eur J Cardiothorac Surg. 2012;41:1117-24.

Key Words: aortic valve, annuloplasty, Ross procedure, root remodeling, aortic annulus

Readers who found these articles interesting may also like to read the following papers found in recent and future issues of our sister publications, Seminars in Thoracic and Cardiovascular Surgery and Operative Techniques in Thoracic and Cardiovascular Surgery!

\section{Acquired: Aortic Disease}

Original Submission: Outcomes of Open Surgical Repair for Type B Dissecting Aortic Aneurysm with Alternative Methods in the Endovascular Stent Era. Mitsumasa Hata. Semin Thorac Cardiovasc Surg 2015; Summer; 27(2):106-112.

Editorial Commentary: It is Difficult to Compare Apples and Oranges: Acute and Chronic Type B Aortic Dissections, Complicated and Uncomplicated, are Different and Should be Treated as Such. Ourania Preventza. Semin Thorac Cardiovasc Surg 2015; Summer; 27(2):113-114.

News and Views: Treatment of Thoracic Aortic Aneurysm: Role of Earlier Intervention. Bulat A. Ziganshin. Semin Thorac Cardiovasc Surg 2015; Summer; 27(2);135-143. 
APPENDIX E1. Patient characteristics according to aortic root procedure (remodeling vs Ross)

\begin{tabular}{|c|c|c|}
\hline Patient characteristics & $\begin{array}{c}\text { Ross } \\
(\mathbf{n}=18)\end{array}$ & $\begin{array}{c}\text { Yacoub } \\
(\mathbf{n}=32)\end{array}$ \\
\hline Mean age (y) & $41.5 \pm 12$ & $43 \pm 14.6$ \\
\hline Male gender, $\mathrm{n}(\%)$ & $16(89 \%)$ & $29(91 \%)$ \\
\hline \multicolumn{3}{|l|}{ Comorbidities } \\
\hline Hypertension, n (\%) & $4(22 \%)$ & $12(38 \%)$ \\
\hline Diabetes, $\mathrm{n}(\%)$ & $0(0 \%)$ & $2(6 \%)$ \\
\hline Dyslipidemia, n (\%) & $2(11 \%)$ & $5(16 \%)$ \\
\hline Obesity, n (\%) & $3(16 \%)$ & $9(28 \%)$ \\
\hline Pulmonary hypertension, n (\%) & $0(0 \%)$ & $1(3 \%)$ \\
\hline \multicolumn{3}{|l|}{ Aortic valve phenotype } \\
\hline Tricuspid, n (\%) & $2(11 \%)$ & $18(56 \%)$ \\
\hline Bicuspid, n (\%) & $8(44 \%)$ & $13(41 \%)$ \\
\hline Unicuspid, n (\%) & $7(37 \%)$ & $1(3 \%)$ \\
\hline Quadricuspid, n (\%) & $1(5.5 \%)$ & $0(0 \%)$ \\
\hline \multicolumn{3}{|l|}{ Connective tissue disorder } \\
\hline Marfan syndrome, n (\%) & $0(0 \%)$ & $7(22 \%)$ \\
\hline Loeys-Dietz syndrome, n (\%) & $0(0 \%)$ & $1(3 \%)$ \\
\hline \multicolumn{3}{|l|}{ Principal valve lesion } \\
\hline Aortic regurgitation, $\mathrm{n}(\%)$ & $3(16 \%)$ & $28(87.5 \%)$ \\
\hline Mixed aortic stenosis/regurgitation, n (\%) & $15(79 \%)$ & $4(12.5 \%)$ \\
\hline \multicolumn{3}{|l|}{ Ring type } \\
\hline Dacron ring, $\mathrm{n}(\%)$ & $17(95 \%)$ & $22(69 \%)$ \\
\hline $\begin{array}{l}\text { ExAo ring (CORONEO Inc, } \\
\text { Montreal, Canada), n (\%) }\end{array}$ & $1(5.5 \%)$ & $10(31 \%)$ \\
\hline \multicolumn{3}{|l|}{ Concomitant procedures } \\
\hline Hemiarch replacement, n (\%) & $3(16 \%)$ & $5(16 \%)$ \\
\hline Mitral valve repair, $\mathrm{n}(\%)$ & $1(5.5 \%)$ & $4(12.5 \%)$ \\
\hline Coronary bypass surgery, $\mathrm{n}(\%)$ & $1(5.5 \%)$ & $2(6 \%)$ \\
\hline
\end{tabular}

APPENDIX E2. Patient characteristics according to type of extraaortic annuloplasty ring implanted

\begin{tabular}{|c|c|c|}
\hline Patient characteristics & $\begin{array}{c}\text { Dacron } \\
(\mathbf{n}=\mathbf{3 9})\end{array}$ & $\begin{array}{c}\text { CORONEO } \\
(\text { ExAo) } \\
(\mathbf{n}=\mathbf{1 1})\end{array}$ \\
\hline Mean age $(y)$ & $42 \pm 14$ & $44.5 \pm 12$ \\
\hline Male gender, $\mathrm{n}(\%)$ & $35(90 \%)$ & $10(90 \%)$ \\
\hline \multicolumn{3}{|l|}{ Comorbidities } \\
\hline Hypertension, n (\%) & $15(38 \%)$ & $1(9 \%)$ \\
\hline Diabetes, $\mathrm{n}(\%)$ & $2(5 \%)$ & $0(0 \%)$ \\
\hline Dyslipidemia, $\mathrm{n}(\%)$ & $6(15 \%)$ & $1(9 \%)$ \\
\hline Obesity, n $(\%)$ & $7(18 \%)$ & $5(45 \%)$ \\
\hline Pulmonary hypertension, $\mathrm{n}(\%)$ & $1(2.5 \%)$ & $0(0 \%)$ \\
\hline \multicolumn{3}{|l|}{ Aortic valve phenotype } \\
\hline Tricuspid, n (\%) & $14(36 \%)$ & $6(54 \%)$ \\
\hline Bicuspid, n (\%) & $16(41 \%)$ & $5(45 \%)$ \\
\hline Unicuspid, n (\%) & $8(20 \%)$ & $0(0 \%)$ \\
\hline Quadricuspid, n (\%) & $1(2.5 \%)$ & $0(0 \%)$ \\
\hline \multicolumn{3}{|l|}{ Connective tissue disorder } \\
\hline Marfan syndrome, n (\%) & $4(10 \%)$ & $3(27 \%)$ \\
\hline Loeys-Dietz syndrome, n (\%) & $1(2.5 \%)$ & $0(0 \%)$ \\
\hline \multicolumn{3}{|l|}{ Principal valve lesion } \\
\hline Aortic regurgitation, $\mathrm{n}(\%)$ & $24(62 \%)$ & $7(64 \%)$ \\
\hline $\begin{array}{l}\text { Mixed aortic stenosis/ } \\
\text { regurgitation, } \mathrm{n}(\%)\end{array}$ & $15(38 \%)$ & $4(36 \%)$ \\
\hline \multicolumn{3}{|l|}{ Operative procedure } \\
\hline Valve-sparing root remodeling, n (\%) & $22(56 \%)$ & $10(90 \%)$ \\
\hline Ross procedure, n (\%) & $17(46 \%)$ & $1(9 \%)$ \\
\hline \multicolumn{3}{|l|}{ Concomitant procedures } \\
\hline Hemiarch replacement, n (\%) & $5(13 \%)$ & $3(27 \%)$ \\
\hline Mitral valve repair, n (\%) & $5(13 \%)$ & $0(0 \%)$ \\
\hline Coronary bypass surgery, $\mathrm{n}(\%)$ & $3(8 \%)$ & $0(0 \%)$ \\
\hline
\end{tabular}

